\title{
The Development of a Risk-Cost Assessment Model for the Evaluation of Fire Safety in Buildings
}

\author{
V. R. BECK \\ Centre for Envionmental Safety and Risk Engineering \\ Victoria University of Technology \\ Melbourne, Australia \\ D. YUNG \\ National Fire Laboratory \\ National Research Council Canada \\ Ottawa, Canada
}

\begin{abstract}
Fire safety and protection facilities to satisfy current regulatory requirements are a significant component of the cost of many buildings. With the development of systematic approaches to building fire safety and protection, designs based on fire safety engineering design techniques offer substantial cost savings while achieving satisfactory levels of life safety.
\end{abstract}

This paper gives an outline of a collaborative research program undertaken by Victoria University of Technology, Australia and the National Research Council of Canada. The purpose of this research collaboration has been the development of a risk-cost assessment model which is used to identify cost-effective fire safety systems in buildings. A description is given of the application of such a model to building projects and code developments in both Australia and Canada.

KEYWORDS: risk, cost, assessment model, fire safety, buildings 


\section{THE DEVELOPMENT OF A FIRE SAFETY ENGINEERING METHODOLOGY}

\section{Performance Objectives for Design}

The major objective of design for the effects of fire in buildings is to achieve satisfactory levels of life safety for: a) occupants of the building of fire origin, b) occupants of adjoining buildings, and c) fire brigade personnel.

Some have argued that the level of property protection in buildings should not be subjected to community regulation, but be a matter for building owners and their insurers. However, the overall costs associated with providing fire safety and protection, and the expected losses from the effects of fire should be minimized.

\section{Performance Assessment Tools}

The level of fire safety in a building is a reflection of a complex interaction between many phenomena, including: fire initiation, fire growth and spread, the response of building components to fire, the response of occupants to the presence of fire, and the response of the fire brigade to the fire. To achieve required levels of safety from the effects of fire in buildings, then it is essential that designers have at their disposal the means to predict the level of life safety for any particular building design and use. The development of the capability to predict the level of life safety requires a model to quantify the performance of the building fire safety system (BFSS).

\section{Cost-effective Designs}

In the design of building fire safety systems, it is appropriate that explicit consideration be given to the level of life safety afforded to occupants of buildings, and to the costs associated with such provision. Such an approach enables designers to undertake a performance-based approach to design, and select the most appropriate cost-effective solution for the BFSS. For a particular building design, the effect of fire was predicted using two performance parameters (Beck[1,2]); namely: the a) expected risk-to-life and b) fire-cost expectation.

No attempt was made to assign monetary value to either the loss of life or the value of lives saved. This avoids serious moral, ethical and economic difficulties which arise when attempting to assign monetary value to human life or suffering.

To identify alternative designs which are considered equivalent to, and more costeffective than, designs conforming with current regulatory provisions, the decision criterion (Beck [2,9]) is: "For an alternative design to be considered acceptable, the expected risk-tolife value shall be equal to or less than the risk-to-life value of a building conforming with the regulations, and the fire-cost expectation for the alternative design shall be less than or equal to the value for the conforming building". With such a comparative approach it is not required to directly compare estimated risk-to-life values, derived from a risk assessment model, with an acceptable level of risk derived from independent sources. This comparative approach also provides some flexibility in the required level of accuracy for the two performance parameters. 
The calculated expected risk-to-life values for designs conforming with current regulatory requirements provide an estimate of current levels of risk to life safety. These risk levels are assumed to be acceptable to the community.

\section{PREVIOUS RISK ASSESSMENT RESEARCH}

Research into risk assessment modelling to consider the effects of fire in buildings was commenced in Australia by Beck in 1979. The aim of this research was to identify costeffective design solutions which would achieve acceptable levels of fire safety for the occupants of buildings. To achieve this aim Beck decided to develop a building fire safety system model which could estimate the level of risk for a particular building. Recognizing that some conceptual models had been developed of the fire safety system, Beck developed a comprehensive system model, based on stochastic state-transition models, to predict the effects of fire in multi-storey, multi-compartment buildings, which included consideration of the effects of various fire-safety and protection subsystems $[1,2,3,4,5]$.

In 1987, Beck undertook a four-month sabbatical period at the National Research Council Canada (NRCC). This lead to the National Fire Laboratory of the NRCC contracting Beck to modify the previously developed risk assessment model for office buildings and to develop a model applicable to Canadian high-rise apartment buildings (Beck [5]). Subsequent research collaboration undertaken between the authors has resulted in three papers of joint authorship $[6,7,8]$.

While the research undertaken during this initial phase has laid the foundation for subsequent research in this area, the risk assessment models contained a number of deficiencies. For example, probabilistic state-transition models were used to characterize fire growth in the enclosure of fire origin. This approach obviated the need to model the physical phenomena involved and the associated times of occurrence of defined events. The submodels used to estimate the probabilities of smoke spread and flame spread were overly restrictive and did not include time effects.

In 1989 Beck was appointed as Visiting Professorial Fellow at the Warren Centre for Advanced Engineering, at the University of Sydney, to lead a project on Fire Safety and Engineering. The Fire Safety and Engineering Project [9] was undertaken during 1989 in conjunction with some 70 Project Fellows. During the Warren Centre project broad consensus was reached on the need for fire safety design to be based on engineering technology, that this technology should form the basis of a performance-based approach to design, and that risk assessment models should be the basis of a rational engineering approach to identify cost-effective fire safety system designs for buildings. Also during the Warren Centre project, demonstration risk assessment models (DRAM) were developed to further investigate the potential applicability of risk assessment models. In the DRAM greater emphasis was placed on modelling the physical phenomena and estimating the times of occurrence of key events. This was achieved in part, by the introduction of design fires at the suggestion of Quintiere during the Warren Centre project.

A sequel to the Warren Centre project was the development of the first draft of a National Building Fire Safety System Code (NBFSSC) [10]. The NBFSSC project was commissioned by the Building Regulation Review Task Force which was established in 
Australia at a Special Premiers' Conference in 1989. The objective of the NBFSSC is to provide flexible and technologically advanced procedures (based on risk assessment modelling) to achieve cost-effective building designs which conform to the fire safety levels implicit in the building regulations. However, to enable the NBFSSC to be published as an Australian Standard, and for it to be routinely applied for design purposes, considerable development is required.

Following the developments of the Warren Centre project, research collaboration between Victoria University of Technology and the National Research Council Canada has lead to the further development and improvement of building fire safety system risk assessment models for both office and apartment buildings. These developments have mainly centred on the inclusion of the concept of design fires, modelling the physical phenomena of fire growth and spread, predicting the time of occurrence of those events relevant to life safety, and the inclusion of fire brigade performance into the model. The resultant model is described in the following section.

\section{CURRENT SYSTEM MODEL}

A brief description of the current system model and the sub-models of the risk-cost assessment model is given in this section [11]. More detailed descriptions are given for the Design Fire Model, Fire Growth Model and the Smoke Spread Model. As for the other submodels, more details can be found in previous publications $[3,4,6-8]$.

The risk-cost assessment model employs an event-based modelling approach in which events are characterized by discrete times and probability of occurrence. The event-based approach is used to define the outcomes of fire growth and spread scenarios in terms of the times of occurrence of untenable conditions. The consequence of these outcomes is in terms of the number of people exposed to untenable conditions.

The risk-cost assessment model for office and apartment buildings assesses the fire safety performance of a fire protection design in terms of two decision-making parameters: the expected risk-to-life (ERL) and the fire-cost expectation (FCE). The ERL is the expected number of deaths over the lifetime of the building divided by the total population of the building and the design life of the building. The FCE is the total fire cost which includes the capital cost for the passive and active fire protection systems, the maintenance cost for the active fire protection systems and the expected losses resulting from fires in the building. The ERL is a quantitative measure of the risk-to-life from all probable fires in the building, whereas the FCE quantifies the fire cost associated with the particular fire safety system design.

To calculate the ERL and FCE values, the risk-cost assessment model considers the dynamic interaction between fire growth, fire spread, smoke movement, human behaviour and the response of fire brigades. These calculations are performed by a number of sub-models interacting with each other as shown in the flowchart in Figure 1.

\section{Design Fire Model}

The risk-cost assessment model uses six design fires in the room of fire origin, and the subsequent fire and smoke spread, to evaluate life risks and protection costs in office and 


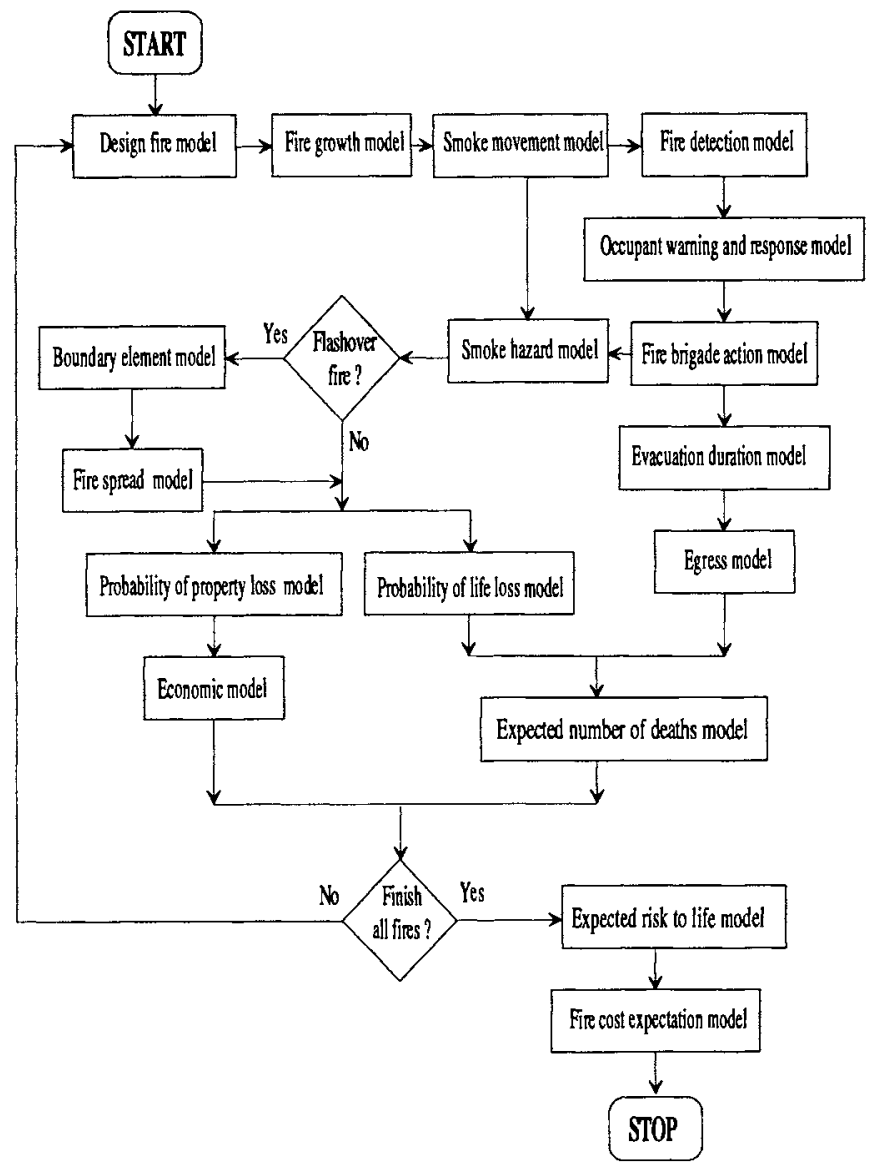

FIGURE 1. Risk-cost assessment model.

apartment buildings. The six design fires, representing the wide spectrum of possible fire types, are:

1. smouldering fire with entrance door open;

2. smouldering fire with entrance door closed;

3. flaming non-flashover fire with entrance door open;

4. flaming non-flashover fire with entrance door closed;

5. flashover fire with entrance door open;

6. flashover fire with entrance door closed.

The probability of occurrence of each design fire, given that a fire has occurred, is based on statistical data. For example in Canada, statistics show that $18 \%$ of all apartment fires reach flashover and become fully developed fires, $63 \%$ are flaming fires that do not reach flashover and the remaining $19 \%$ are smouldering fires that do not reach the flaming stage 
[12]. If sprinklers are installed, the model assumes that some of the flashover and nonflashover fires, depending on the reliability and effectiveness of the sprinkler system, are rendered non-lethal.

The risk-cost assessment model evaluates the effects of multiple fire scenarios which may occur in the building during the life of the building. For example in an apartment building, a fire scenario is the fire and smoke spread scenario resulting from one design fire, in any one of the apartment units in the building and during a time when the occupants are either awake or asleep. The number of fire scenarios, therefore, is the product of the number of design fires, the number of apartment units and whether the occupants are awake or asleep.

\section{Fire Growth Model}

The fire growth model predicts the development of the 6 design fires in the room of fire origin. Details of this model for apartment buildings are described in a previous paper [13]. The model calculates the burning rate, room temperature and the production and concentration of toxic gases as a function of time. With these calculations, the model determines the time of occurrence of 5 important events: (1) time of fire cue; (2) time of smoke detector activation; (3) time of sprinkler activation; (4) time of flashover; and (5) time of fire burnout. The first three detection times are used later by the Evacuation Duration Model to estimate the time available for evacuation; the flashover time is used by the Fire Brigade Action Model to evaluate the effectiveness of fire fighting; and the burnout time is used by the Smoke Hazard Model as part of the calculation for the maximum smoke hazard. The model also predicts the mass flow rate, the temperature and the concentrations of $\mathrm{CO}$ and $\mathrm{CO}_{2}$ in the hot gases leaving the fire room. This latter information is used by the Smoke Movement Model to calculate the spread of smoke to different parts of the building as a function of time.

\section{Smoke Movement Model}

The smoke movement model calculates the spread of smoke and toxic gases to different parts of the building as a function of time. Details of this model are described in a previous publication [14]. The model also calculates the critical time when the stairs become untenable, which is considered to be the time when the occupants are trapped in the building. This critical time is used later by the Evacuation duration model to calculate the duration available for evacuation.

\section{Fire Detection Model}

The fire detection model calculates the probabilities of detection at the first three detection times mentioned under the Fire Growth Model. This information is used later by the Egress Model to model the evacuation of the occupants.

\section{Occupant Waming and Response Model}

The occupant warning and response model calculates the probabilities of warning and response at the first three detection times mentioned under the Fire Growth Model. This information is used later by the Egress Model to model the evacuation of the occupants.

\section{Fire Brigade Action Model}

This model calculates the probability and time of arrival of the fire brigade. This model also evaluates the effectiveness of fire fighting, based on the flashover time from the Fire 
Growth Model and the arrival time of the fire brigade. The information on arrival and effectiveness of the fire brigade is used by the Smoke Hazard Model to calculate the maximum smoke hazard to the occupants and the Fire Spread Model to calculate the probabilities of fire spread.

\section{Smoke Hazard Model}

This model calculates the maximum smoke hazard to the occupants based on the burnout time from the Fire Growth Model and the arrival time and effectiveness of the fire brigade from the Fire Brigade Action Model. This information is used later in the Life Loss Model to calculate the probabilities of life loss.

\section{Evacuation Duration Model}

This model uses the three fire detection times from the Fire Growth Model and the critical time in the stairs from the Smoke Movement Model to calculate three durations available for evacuation.

\section{Egress Model}

Based on the evacuation time available, this model calculates the number of occupants who have evacuated the building and those who are trapped in the building. This information is used later by the Expected Number of Deaths Model to calculate the number of deaths.

\section{Boundary Element Model}

This model calculates the probabilities of failure of the boundary elements (walls, floors, doors, etc.) as a result of flashover fires.

\section{Fire Spread Model}

Based on the probabilities of failure of the boundary elements and the effectiveness of the fire brigade, this model calculates the probabilities of fire spread to different parts of the building. This information is used later by both the Property Loss Model and the Life Loss Model to calculate fire losses and life losses.

\section{Life Loss Model}

Based on the probabilities of smoke hazard from the Smoke Hazard Model and fire spread from the Fire Spread Model, this model calculates the probabilities of life loss.

\section{Expected Number of Deaths Model}

Based on the probabilities of life loss from the Life Loss Model and the number of occupants trapped in the building from the Egress Model, this model calculates the expected number of deaths in the building.

\section{Property Loss Model}

Based on the probabilities of fire spread from the Fire Spread Model, this model calculates the expected property loss.

\section{Economic Model}

Based on the expected property loss and the capital and maintenance costs of the fire protection systems, this model calculates the expected fire costs. 


\section{Expected Risk to Life Model}

This model calculates the overall expected risk-to-life (ERL) by summing the expected number of deaths in the building for each fire scenario and the probability of each fire scenario,

\section{Fire Cost Expectation Model}

This model calculates the fire cost-expectation (FCE) using the capital and maintenance costs of the fire protection systems, the expected fire losses for each fire scenario and the probability of each fire scenario.

\section{ASSUMPTIONS AND LIMITATIONS}

In the risk-cost assessment model, due to the complexity and the lack of sufficient understanding of fire phenomena and human behaviour, certain conservative assumptions and approximations were made in the mathematical modelling. In addition, not all aspects of the risk-cost assessment model have been fully verified by full-scale fire experiments or actual fire experience. Only some of the submodels have been verified by experiments or statistical data.

As a result, the predictions made by the model can only be considered as approximate. The model, therefore, should not be used for absolute assessments of life risks and protection costs. For comparative assessments of life risks and protection costs, and for the selection of a cost-effective fire safety system design solution, the model is considered to be reliable.

As in many computer models, the model uses certain input parameters to describe the characteristics of various fire safety designs. These include the fire resistance rating of boundary elements, the reliability of smoke alarms and sprinklers, the probability of door open or closed and the response time of fire brigades. Sensitivity of these parameters on the predicted risks have been checked and found to be reasonable [15].

\section{CASE STUDY}

In this paper, the life risks of various fire protection designs for a proposed 3-storey apartment building in Australia are evaluated as a case study using the risk-cost assessment model [16]. This case study was carried out at the request of the National Association of Forest Industries of Australia (NAFI), to support their proposal to the Australian Uniform Building Regulations Coordinating Council (AUBRCC) for changes to the Building Code of Australia (BCA) to permit the construction of 3-storey timber-framed apartment buildings. In this study, the risk-cost assessment model was used to compare the fire safety performance of 3-storey timber-framed apartment buildings, with various fire protection designs, with that of the code-compliant concrete/masonry construction. The objective was to'determine whether 3-storey timber-framed apartment buildings, with proper fire protection, could be as safe as concrete/masonry construction.

Figure 2 shows the floor plan of the prototype 3-storey apartment building being considered in Australia. Each floor has four apartment units: two 2-bedroom units $\left(96.3 \mathrm{~m}^{2}\right.$ each) and two 3-bedroom units $\left(129.7 \mathrm{~m}^{2}\right.$ each). The four units on each floor are planned around an open, central staircase with direct access to it from any of the four apartment 


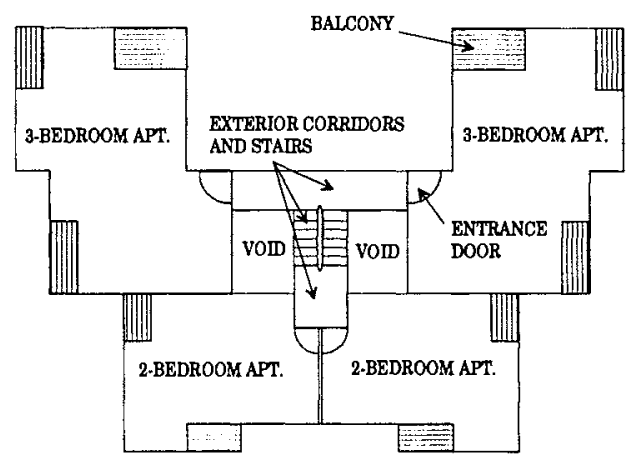

FIGURE 2. Prototype floor plan.

entrance doors. To ensure safe passage for evacuation, an open staircase is used and all apartment entrance doors facing it are fire-rated and with self-closing devices. In addition, all entrance doors are recessed from the staircase. This would prevent direct flame impingement on the staircase in the event that flames emerge from an entrance door.

TABLE 1. Fire protection options.

\begin{tabular}{cccccc}
\hline Option & Frame & $\begin{array}{c}\text { Internal Wall and } \\
\text { Floor Acoustic } \\
\text { Insulation }\end{array}$ & $\begin{array}{c}\text { Internal Wall and } \\
\text { Floor Fire Resistance } \\
\text { Rating (FRR) }\end{array}$ & $\begin{array}{c}\text { Exterior } \\
\text { Cladding }\end{array}$ & $\begin{array}{c}\text { Central } \\
\text { Fire } \\
\text { Alarm }\end{array}$ \\
\hline 1 & Concrete/masonry & None & $180 \mathrm{~min}$ & Brick & No \\
2 & timber & None & $20 \mathrm{~min}$ & Timber & No \\
3 & timber + FRR & None & $60 \mathrm{~min}$ & Timber & Yes \\
4 & timber + FRR & None & $60 \mathrm{~min}$ & Brick & Yes \\
5 & timber + FRR & BCA-compliant & $75 \mathrm{~min}$ & Brick & Yes \\
6 & timber + FRR & Higher & $120 \mathrm{~min}$ & Brick & Yes \\
\hline
\end{tabular}

Based on the prototype design, five different fire protection options were considered for the timber-framed construction and compared to the reference BCA (Building Code of Australia)-compliant concrete/masonry option. These options are summarized in Table 1. Option 1 is the reference BCA-compliant concrete/masonry option. Option 2 is the unprotected timber-framed option. Option 3 is the same timber-framed construction as in Option 2 but with barriers having a 1-hour fire resistance rating and a central alarm system consisting of individual smoke detectors which are connected to a central alarm. Options 4 to 6 are the same as Option 3 but with exterior brick cladding (higher fire resistance to external fire spread) and three levels of acoustic insulation (higher interior fire resistance rating). 


\section{Results}

The risk-cost assessment model was used to determine the values of the two performance parameters, the expected risk-to-life (ERL) and the fire-cost expectation (FCE), for the six design options shown in Table 1. In this paper, only the ERL values are shown to compare the relative fire safety performance of timber-framed and concrete/masonry construction. The FCE values are not discussed in this paper. However, they are consistent with the cost estimates by NAFI that 3-storey timber-framed apartment buildings, if permitted, are more cost effective than similar concrete/masonry buildings.

The expected risk-to-life (ERL) values obtained by the risk-cost assessment model for the six design options are shown in Figure 3. In this figure, the ERL values have been normalized by that of the reference concrete/masonry option (Option 1), to provide a relative comparison of the five timber options with the concrete/masonry option. Option 2, which is the basic timber option without fire resistance rating or an alarm system, is shown, as expected, to have the highest relative ERL value (2.32). Option 3, timber-framed construction with a 1-hour fire resistance rating and a central alarm system, is shown to reduce the relative ERL value to a level (0.93) slightly lower than that of the reference concrete/masonry option. Options 4 to 6 are timber-framed constructions with exterior brick cladding and 3 levels of acoustic insulation. The results show that these additional fire resistances have little or no influence on the ERL.

The results in Figure 3 show that timber-framed options with proper fire resistant designs and a central alarm system can be as safe as the reference concrete/masonry design without a central alarm system. With a minimum 1-hour fire resistance rating and a central alarm system, the occupants in such timber buildings would have left the building via the exterior central staircase long before the fire could spread and thus pose any significant hazard. The concrete/masonry option may have the advantage of a higher fire resistant construction but lacks a central alarm to warn the occupants. These findings are consistent with an earlier Japanese full-scale fire experiment conducted in December 1991 [17].

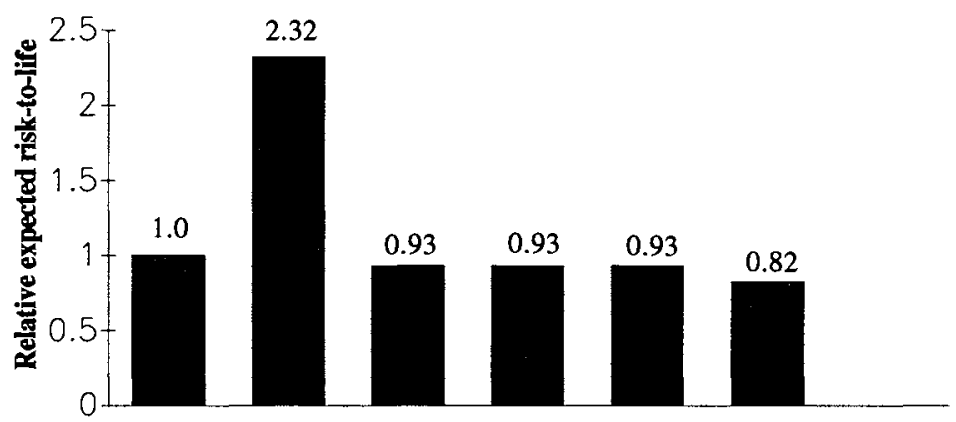

Option 1 Option 2 Option 3 Option 4 Option 5 Option 6

Design options

FIGURE 3. Relative expected risk-to-life for 6 design options shown in Table 1. 
The results in Figure 3 also show that timber options, with proper fire resistant designs and a central alarm system (Options 3 to 6), can reduce the risk to life by about $60 \%$ when compared with the timber option with no fire protection (Option 2). This is consistent with statistical findings that show that the installation of smoke detectors alone reduces the number of deaths from fires in buildings by about $50 \%$ [18].

\section{FUTURE RESEARCH COLLABORATIONS}

Recently the National Fire Laboratory, National Research Council Canada and the Centre for Environmental Safety and Risk Engineering, Victoria University of Technology have held detailed discussions and reached agreement on a collaborative research program for the next several years. The focus of this collaboration is as follows: a) full-scale experimental validation of submodels, b) development of improved submodels and c) validation of models using complex numerical techniques such as computational fluid dynamics and Monte Carlo simulation. The future development and application of the risk-cost assessment model, as the basis of a performance-based approach for building code reform and the introduction of a fully-engineered approach for the design of building fire safety systems, is planned for Australia and is being considered in Canada.

\section{CONCLUSIONS}

The development of a fire safety engineering methodology to identify cost-effective fire safety systems in buildings based on a systematic approach, which combines both physical and risk assessment modelling, is a challenging task. The essential nature of this task is to develop reliable models to predict the level of life safety which are applicable to a wide range of occupancies. The execution of this task requires the aggregation of substantial resources. If this task is to be completed in a reasonable time period it will be necessary for several research organizations to combine their efforts through an integrated research and implementation program which combines the specialized skills and facilities from each research organization.

This paper outlines a collaborative research effort between the Victoria University of Technology and the National Research Council of Canada into the development of a risk-cost assessment model which is used to identify cost-effective fire safety systems in buildings. This research collaboration has been in progress for some five years. Recently an agreement was reached to extend the research collaboration over the next several years. It is expected that this research collaboration will assist to achieved significant application of the risk-cost assessment model for building code reform, the development of new performance-based design codes and for specific building projects in both Canada and Australia.

\section{REFERENCES}

1. Beck, V.R., "Outline of a Stochastic Decision-Making Model for Building Fire Safety and Protection", Fire Safety Journal, Vol.6, No.2, 1983, pp.105-120.

2. Beck, V.R., "Cost-Effective Fire Safety and Protection Design Requirements for Buildings", PhD Thesis, University of New South Wales, July 1986.

3. Beck, V R, "A Cost-Effective Decision-Making Model for Building Fire Safety and Protection", Fire Safety Journal, Vol.12, 1987, pp.121-138. 
4. Beck, V.R. and Poon, S.L., "Results From a Cost-Effective Decision-Making Model for Building Fire Safety and Protection", Fire Safety Joumal, Vol.13, 1988, pp.197-210.

5. Beck, V R., "Cost-Effective Fire Safety and Protection Design Requirements for Canadian Apartment Buildings", Contract Report for the National Research Council Canada, Footscray Institute of Technology, Melbourne, Australia, May 1988, 161pp.

6. Beck, V.R. and Yung, D., "A Cost-Effective Risk-Assessment Model for Evaluating Fire Safety and Protection in Canadian Apartment Buildings", International Fire Protection Engineering Institute, 5th Conference, Ottawa, Ontario, Canada, May 21-31, 1989, Volume 1 Papers.

7. Yung, D. and Beck, V.R., "A Risk-Cost Assessment Model for Evaluating Fire Risks and Protection in Apartment Buildings", International Symposium on Fire Engineering for Building Structures and Safety, The Institution of Engineers, Australia, Melbourne, November 14-15, 1989, pp.15-19.

8. Beck, V.R. and Yung, D., "A Cost-Effective Risk-Assessment Model for Evaluating Fire Safety and Protection in Canadian Apartment Buildings", Journal of Fire Protection Engineering, Vol.2, No.3, 1990, pp.65-74.

9. Warren Centre "Project Report" and "Technical papers, Books 1 and 2", Fire Safety and Engineering Project, The Warren Centre for Advanced Engineering, The University of Sydney, Australia, December 1989.

10. Beck, V. R.et al "Draft National Building Fire Safety Systems Code", in Building Regulation Review Task Force, "Microeconomic Reform: Fire Regulation", Department of Industry Technology and Commerce, Canberra, Australia, May 1991, 165 pp.

11. Yung, D., G.V. Hadjisophocleous and Takeda, H., "Comparative Risk Assessments of 3Storey Wood-Frame and Masonry Construction Apartment Buildings", Proceedings of Interflam '93, Oxford, England, March 30 - April 1, 1993, pp. 499-508.

12. Gaskin, J. and Yung, D., "Canadian and U.S.A. Fire Statistics for Use in the Risk-Cost Assessment Model", IRC Internal Report No. 637, National Research Council Canada, Ottawa, Canada, January 1993.

13. Takeda, H. and Yung, D., "Simplified Fire Growth Models for Risk-Cost Assessment in Apartment Buildings", J. of Fire Protection Engineering, Vol.4, No.2, 1992, pp.53-66.

14. Hadjisophocleous, G.V. and Yung, D., "A Model for Calculating the Probabilities of Smoke Hazard from Fires in Multi-Storey Buildings", J. of Fire Protection Engineering, Vol.4, No.2, 1992, pp.67-80.

15. Hadjisophocleous, G.V. and Yung, D., "Parametric Study of the Fire Risk-Cost Assessment Model for Apartment and Office Buildings", IRC Internal Report (in preparation), National Research Council Canada, Ottawa, Canada, 1993.

16. Yung, D. and G.V. Hadjisophocleous, "The Use of the NRCC Risk-Cost Assessment Model to Apply for Code Changes for 3-Storey Apartment Buildings in Australia", Proceedings of the Symposium on Computer Applications in Fire Protection Engineering, Worcester, Massachusetts, June 28-29, 1993, pp.57-62.

17. Hasemi, Y., "Wooden 3-Storey Apartment Building Shake and Burn Test Report", Building Research Institute, Tsukuba, Japan, January 1992 (in Japanese).

18. "Review of Automatic Sprinkler Protection for Buildings in Canada", Professional Loss Control Ltd., Fredericton, New Brunswick, February 1992. 